\title{
Pilot, Open and Non-controlled Trial to Assess the Objective Parameters which Correlate Knee Mobility with Pain Reduction in Patients Affected by Knee Osteoarthritis and Treated with Oral Hyaluronic Acid
}

\author{
BOGDAN CORNELIU ANDOR ${ }^{1}$, SIMONA CERBU ${ }^{2}$, DIONISIO FRANCO BARATTINI ${ }^{3}$, DUMITRU EMANUEL DOGARU ${ }^{3}$, \\ OVIDIU DULGHERU4 ${ }^{4}$, SIMONE GUADAGNA3 ${ }^{3}$, SERBAN ROSU5* \\ ${ }^{1}$ University of Medicine and Pharmacy Victor Babes, Dept. of Orthopaedics-Traumatology II, 2 Eftimie Murgu Sq., 300041, Timisoara \\ Romania \\ 2 University of Medicine and Pharmacy Victor Babes, 2 Eftimie Murgu Sq., 300041, Timisoara, Romania \\ ${ }^{3}$ Opera CRO, 10 Cozia Str. 300209, Timisoara Romania \\ ${ }^{4}$ Independent Researcher \\ ${ }^{5}$ University of Medicine and Pharmacy Victor Babes, Department of Oral and Maxillo-Facial Surgery, 2 Eftimie Murgu Sq., 300041, \\ Timisoara, Romania
}

The study was in preparation for a future randomized clinical trial (RCT) with oral hyaluronic acid (HA) in knee osteoarthritis. Its purpose was to evaluate the feasibility of i) ultrasonography (US) and range of motion (ROM) parameters as objective measurements to correlate the improvement of knee mobility with its pain reduction; ii) the planned recruitment monthly rate to estimate the resources for the main study. In addition, it should give by US, ROM, visual analogue scale (VAS) and KOOS questionnaire, preliminary data on efficacy. This open-label pilot trial was performed in an orthopedic clinic (Timisoara, Romania). Male and female subjects (from 50 to 70 years) diagnosed with symptomatic $O A$ of the knee with i) mild joint discomfort for at least 6 months, ii) Kellgren/Lawrence score 2 by X-ray, iii) pain for at least 15 of the 30 previous days, were included. Exclusion criteria were: inflammatory arthritic condition; oral corticosteroids within 4 weeks; intra-articular injections of HA or corticosteroids within 3 months; anti-inflammatory or chondroprotective drugs within 2 weeks. Following protocol, 8 patients administered for 8 weeks Syalox ${ }^{\circledR}$ 300 Plus (River Pharma, Italy) a product based on HA of high molecular weight. US parameters improved from baseline, even if no statistically significant differences were found. ROM and VAS (at rest, on moving and on pressing) values improved significantlyat week 4 and 8 in comparison with baseline. The correlation between objective improvement of knee mobility and subjective pain reduction was documented. The enrolment rate was 8 patients/month. The KOOS subscales scores evidenced statistically significant differences during the study. No adverse event. US and ROM can be used as objective measurements to correlate improvement of knee mobility with pain reduction. The recruitment capability evidenced a realistic estimation of time and budget for the main study. Preliminary data on efficacy using objective measurements (US, ROM) and subjective parameters (VAS, KOOS questionnaire) showed significant improvements and will be used for sample size calculation in the main study.

Keywords: Pilot trial, feasibility study, knee osteoarthritis, hyaluronic acid, outcome assessment

Osteoarthritis $(O A)$ is one of the most common chronic condition of joints in older adults, affecting more than one third of persons older than 65 years of age [1]. Itis currently estimated that $80 \%$ of $\mathrm{OA}$-affected individuals exhibit marked limitations in the normal range of motion of joints, with $20 \%$ of subjects not being able to perform major activities of daily living and $11 \%$ of subjects requiring personal care [2,3]. Knee serves as the most common site of $O A$ and functional impairments associated to this degenerative disease are commonly encountered in people aged 50 years or older [4].

Even though there are discrepancies due to the heterogeneity of opinion leaders involved, the international evidence-based guidelines agree that knee OA management requires, both non-pharmacological, and pharmacological approaches [5].

The treatment algorithm recommendation developed by the European Society for Clinical and Economic Aspects of Osteoporosis and Osteoarthritis (ESCEO) for knee OA provides practical guidance for prioritizing interventions in this degenerative disease, making its management more easily accessible to physicians [6,7]. This harmonization algorithm involves the initiation of background therapy with chronic symptomatic slow acting drugs for OA (SYSADOAs) -with the addition of paracetamol as short-term rescue analgesia when needed -as the preferential approach to the first step of pharmacological treatment of this degenerative joint disease [6]. SYSADOAs display an excellentsafety and tolerability profile and includes natural compounds consisting of repeating disaccharides, such as glucosamine sulphate, chondroitin sulphate, hyaluronic acid (HA), diacerein, and avocado-soy bean unsaponifiable [7-9]. In particular, HA has been largely studied over the last decade and its efficacy after intra-articular (IA) administration in patient with mild to moderate knee OA was evidenced in randomized clinical trial (RCT) with more than 137 studies reported in a recent meta-analysis and in real life setting surveys [10-12]. On the contrary, it is not yet clarified which is its bioavailability in humans after HA oral administration (despite direct evidence of ingested $\mathrm{HA}$ reaching the knee joints in human-relevant pre-clinical mammalian models [13-15] and the number of clinical 
trials is quite small and with several inconsistencies. The recent review analysing studies from 2008 to 2015 and the systematic review updated to J anuary 2018 concluded that efficacy of oral HA in relieving knee pain, was demonstrated in various clinical trials without any side effects but evidenced the heterogeneity of efficacy endpoints used $[16,17]$. On the one hand, many studies have relied almost exclusively on measuring subjective parameters for pain as the visual analogue scale (VAS) or specific scores for osteoarthritis outcome, such as the Western Ontario and McMaster Universities Osteoarthritis Index (WOMAC), the Knee injury and Osteoarthritis Outcome Score (KOOS) or scales tested in Japanese population only, JKOM and J OA [18-20]. On the other hand, objective measurement methods based on ultrasonography (US), on isokinetic dynamometry, have been used in several investigations, but with rather ambiguous results [21-24]. The quantification of range of motion (ROM) of the knee joint measured with a goniometer, which remains the simple and most widely used tool in daily practices by orthopedists, was never used as an efficacy endpoint in the analyzed trials. This tool, although not the best way of assessing patients' disability in severe OA might be used in connection with scales like VAS and KOOS to improve the evaluation of OA patients [25]. To overcome the above mentioned critical issues, we had planned to testin a new clinical trial the hypothesis that the oral administration of HMWHA for a period of 4 months would: i) reduce the pain of the affected knee at the end of the study period; ii) evidence a statistically significant difference versus a control population treated with placebo; iii) evidence the above mentioned improvement by both subjective measurements (VAS, $\mathrm{OoL}$ ) and objective measurements (i.e. US, ROM). After the conclusion of the study period the patient had the opportunity (even not mandatory) to enter in a follow up period of 8 additional months. This attractive hypothesis could represent a hazard in term of management, money, time for our team of investigators with limited resources. For this reason, we have planned first a pilot study to assess the feasibility of parameters (US, ROM) as objective measurements able to correlate the improvement of knee mobility with its pain reduction. This pilot study, according to the Ashanti saying no one tests the depth of a river with both feet [26], should avoid dangerous consequences of starting the large population trial with potential bias in the choice of end points and their measurement [27]. In addition, the pilot study should assess the feasibility of the planned recruitment monthly rate and, consequently estimate the time and the budget that will occur during the main study; and it should give (by US, ROM, VAS, KOOS) preliminary, but not exhaustive, data on efficacy of the tested product [28].

Considering the PICOT format, we have assumed the following research question: could a pilot sample of 8 patients from 50 to 70 years, with the oral administration of high-molecular-weight HA $300 \mathrm{mg}$ assess the feasibility of the main study -in terms of planned outcomes, time, and resource needed in the 8-week study duration? [29].

\section{Expeirmental part}

Materials and methods

Study design and objectives

This pilot trial was performed with an open-label single center design. The study objective was to assess the feasibility of implementing in a future main study the techniques of US and ROM as specific objective measurements and to correlate the improvement of knee mobility with pain reduction evaluated by VAS in patients assuming oral HA. Additional objectives were: to verify if the actigraph, a novel device already tested in previous clinical trials was able to give an indirect evaluation of pain, quantifying basic body movements like walking or performing daily activities; to collect data about recruitment capability and study procedures, to have an estimation of time and budget for the main study; to obtain preliminary data on efficacy for the sample size calculation of the main study.The involved site was SC Medicali's, a private clinic specialized in orthopedics located in Timisoara (Romania).

\section{Inclusion exclusion criteria}

Male or female subjects between 50 to 70 years were included. They were diagnosed with symptomatic OA of the knee with mild joint discomfort for at least 6 months following ACR criteria [30]. The inclusion criteria also requested confirmatory diagnosis (Kellgren/Law rence score 2 ) at the evaluated knee joint by X-ray performed within the previous 6 months and pain for at least 15 of the 30 days prior to the start of the study [31]. Additional inclusion criteria were an informed consent (IC) form signed by patients and compliance to all study requirements. Exclusion criteria included the presence of any inflammatory arthritic condition different from knee $\mathrm{OA}$; fibromyalgia, multiple sclerosis, or autoimmune disorder; treatment with oral corticosteroids within four weeks or with intra-articular injections of HA or corticosteroids in the target joint within three months; oral intake of anti-inflammatory or chondroprotective drugs two weeks before the selection; the use of HA-containing nutritional supplements or cosmetics within one month prior to the beginning of the study; previous or concomitant surgical treatment of knee joint; significant injury to the target joint within the past 6 months; energy-restricted diet for weight loss; pregnant women, nursing mothers, or women (only if childbearing potential) not using adequate methods of contraception; patients with cardiovascular, hepatic, renal, respiratory, or hematologic illness, or medical condition that would compromise participation to the study; and participation in an interventional clinical study in the previous 30 days. Throughout the clinical trial, the subjects were not allowed alcohol consumption, drug abuse, energy-restricted diet for weightloss, use of diuretics and any medication mentioned in exclusion criteria; and routine intake of antiresorptive drugs, including bisphosphonates or oestrogen. There was no restriction on treatments taken previously by subjects for clinical conditions not related to the study condition.

\section{Product administration}

All patients received, Syalox ${ }^{\circledR} 300$ Plus (River Pharma, Orio Litta- Italy). The administered product contained HA of high molecular weight ( $>2.8$ MillionDa) and Boswellia extract containing $10 \%$ Acetyl Keto â Boswellic Acid. The tested product was administered for 8 weeks, 1 tablet a day.

\section{Outcomes}

The primary outcome was the correlation between parameters collected using objective measurements (US and ROM) and that one evaluated using a subjective tool (VAS at rest). As secondary outcomes, we have used the associations between the improvements in VAS on moving and on pressing and those observed in US- and ROM-related variables, the patient recruitment monthly rate to verify the feasibility for time and budget of the planned future main study. As far as safety, we monitored the occurrence 
of any adverse event during the study. The following exploratory outcomes were also planned, to obtain data for sample size calculation of the main study: preliminary efficacy data belonging to KOOS Questionnaire Romanian version, VAS at rest, on moving on pressing, ROM, rescue medication use, and feasibility of using data obtained with actigraphy.

Imaging outcomes were evaluated via US by the presence or absence of the following: synovial fluid, articular cartilage damage, medial meniscal protrusion, lateral meniscal protrusion, medial osteophytes, lateral osteophytes, enthesopathies, Baker's cysts [32].

ROM was evaluated using a goniometer to measure the active and passive flexion and extension, respectively of the affected knee.

The VAS values were obtained using the validated scale of $100 \mathrm{~mm}$ measuring the patient's level of pain at resting, moving, and pressing [33].

The KOOS Questionnaire Romanian version, a patientadministered test, was chosen for its characteristics to be used over short- and long-term time intervals [34]; it was tested in this pilot study after 4 and 8 week interval, while in the main study it will be assessed at week 16 and 32 . KOOS consists of 5 subscales: pain, other symptoms, function in daily living, function in sport and recreation and QoL. Standardized answer options are given (5 Likert boxes) and each question is assigned a score from 0 to 4.
A normalized score (100 indicating no symptoms and 0 indicating extreme symptoms) is calculated for each subscale. The results of the 5 subscales were plotted as an outcome profile in a graph with scores from 0-100 on the $y$-axis and the five subscales on the $x$-axis.

The actigraph was placed below the patient knee by an elasticated band with Velcro for 7 days prior baseline (BL) and for 7 days before final visit. The device should not be removed by the patient, but only by the Investigator during the visits (except when having a shower). Thanks to a battery-powered motion sensor itshould be able to collect the data related to patient movements as quantitative pattern $24 \mathrm{hrs}$ a day for 1 week.

To verify the amount of rescue medication consumed during the study period, the patient received at $B L 2$ boxes of paracetamol $500 \mathrm{mg}$ (40 tablets in total) and were instructed to report on diary cards their administration. At the final visit, the Investigator checked the quantity of the returned paracetamol and compared the amount with the data written in the diary cards.

\section{Framew ork of the study}

The trial required three visits per each patient, with the baseline (BL) visit, the second visit, and the last visit taking place at the start of the trial, at four weeks ( \pm two days), and at eight weeks ( \pm four days), respectively (Figure 1). At the BL visit, patients were examined to check

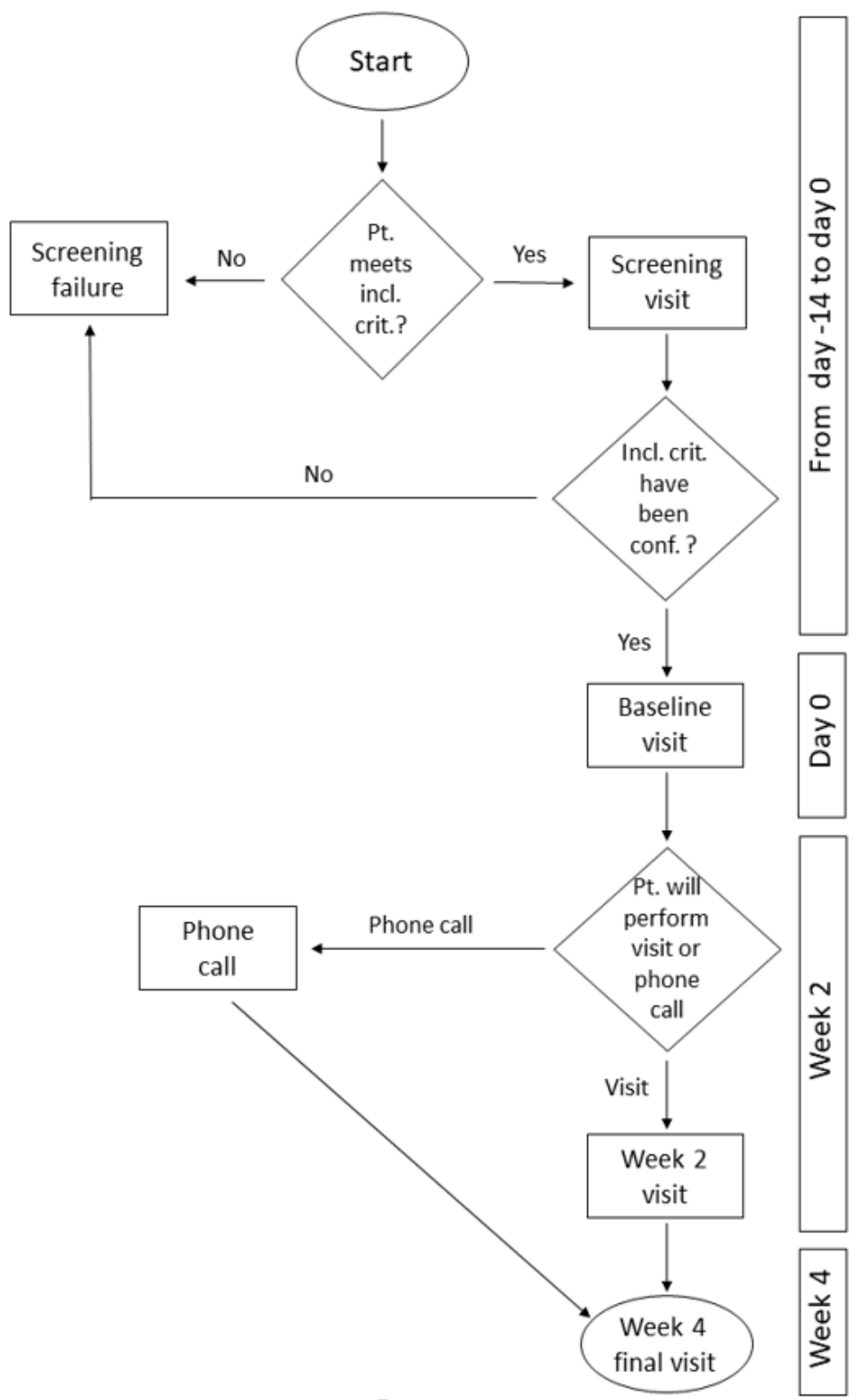


whether they meet the selection criteria and were subjected to a routine orthopaedic evaluation to confirm the knee OA diagnosis. At the start of the clinical study, each patient received the tested product Syalox ${ }^{\circledR} 300$ Plus (RiverPharma, Orio Litta, Italy) for eight weeks and two boxes of $500 \mathrm{mg}$ paracetamol ( 40 pills) to be used as shortterm rescue analgesia (when required) and was instructed to complete the diary cards with data on drug administration. The US-related outcomes were determined at the start and the end of the study, whereas the ROM, VAS, and KOOS related outcomes were recorded at each visit. The actigraph was placed above the affected knee two times: 7 days before the BL (removed in the BL) and 7 days before the week 8 visit (removed in the final visit).

\section{Statistical methods}

Since this was a pilot study, a sample size calculation was not performed. We estimated to enrol 8 patients as around $10 \%$ of the number required for the main future RCT. The level of significance of $<0.5$ was considered statistically significant at $95 \%$ confidence interval. If a subject was missing information for one or more variables. Safety was evaluated in terms of adverse event findings. Analysis comparing the in between visits values were done using t-testfor demographic parameters, body mass index
(BMI), and VAS, McNemar test for US, Wilcoxon signedrank test for ROM and KOOS. Pearson correlation coefficient was calculated between VAS and ROM and between VAS and US parameters. Statistical analysis was performed using SAS 9.2 (SASInstitute Inc., Cary, NC, USA).

\section{Ethics}

The study protocol was approved by a local independent ethical committee in Timisoara on December 12, 2017, registered in clinicaltrials.gov as NCT 03421054, and shared by fully open access [35]. The study was performed in accordance with the ethical principles of the current version of the Declaration of Helsinki (64th WMA General Assembly, Fortaleza, Brazil, October 2013) and the Directive 91/507/EEC, Guidelines for GCP. The privacy of patient data was protected following the 677/21 November 2001 law in Romania.

\section{Results and discussions}

Out of 8 patients enrolled, no one withdrew from the study and all were included in the per-protocol analysis. The Consort flow diagram is reported in Figure 2.

Participants were recruited from February 15th, 2018 to March 19th, 2018; May 25th, 2018 was the date for the last visit of the last patient. Therefore, the enrolment rate was 8 patients/month in total. This value was coherent with the monthly site recruitment rate planned for the main RCT (at least 5 patients/month/site). It must be emphasized

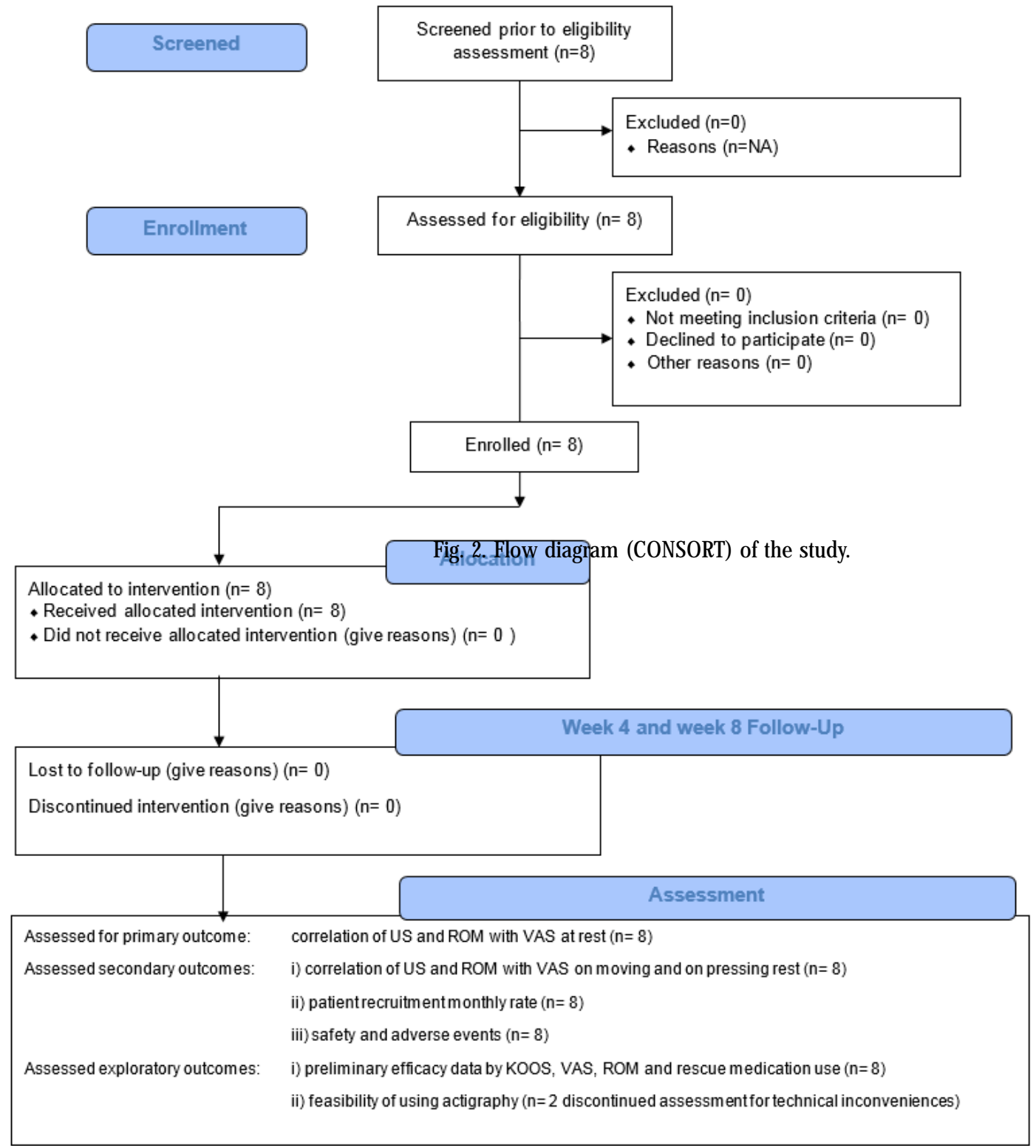

Fig. 2. Flow diagram (CONSORT) of the study. 


\begin{tabular}{|c|c|c|c|c|c|c|c|c|}
\hline Characteristic & Category & $\mathbf{N}$ & Mean \pm SD & Median & Minimum & Maximum & p-value & \\
\hline \multirow[t]{3}{*}{ Age (years) } & Male & 5 & $56.40 \pm 6.19$ & 56.0 & 49 & 64 & \multirow{3}{*}{$p=0.056$} & \multirow{12}{*}{$\begin{array}{c}\text { Table } 1 \\
\text { DEMOGRAPHY OF } \\
\text { PATIENTS } \\
\text { Significant differences } \\
\text { are marked with * }\end{array}$} \\
\hline & Female & 3 & $68.00 \pm 7.63$ & 68.0 & 67 & 69 & & \\
\hline & All & 8 & $50.62 \pm 13.12$ & 62.5 & 49 & 69 & & \\
\hline \multirow[t]{3}{*}{ Height (cm) } & Male & 5 & $181.00 \pm 11.02$ & 178.0 & 169 & 199 & & \\
\hline & Female & 3 & $164.33 \pm 2.08$ & 164.0 & 162 & 166 & $p=0.046^{*}$ & \\
\hline & All & 8 & $174.75 \pm 12.04$ & 173.5 & 162 & 199 & & \\
\hline \multirow[t]{3}{*}{ Weight (kg) } & Male & 5 & $84.80 \pm 5.54$ & 83.0 & 78 & 91 & & \\
\hline & Female & 3 & $65.33 \pm 8.96$ & 70.0 & 55 & 71 & $\mathrm{p}=0.009^{*}$ & \\
\hline & All & 8 & $77.50 \pm 11.92$ & 80.00 & 55 & 91 & & \\
\hline \multirow[t]{3}{*}{ Body Mass Index $\left(\mathrm{kg} / \mathrm{m}^{2}\right)$} & Male & 5 & $25.98 \pm 1.99$ & 26.20 & 22.70 & 27.80 & & \\
\hline & Female & 3 & $24.17 \pm 2.74$ & 25.70 & 21.00 & 25.80 & $p=0.316$ & \\
\hline & All & 8 & $25.30 \pm 2.30$ & 25.85 & 21.00 & 27.80 & & \\
\hline
\end{tabular}

that the result was obtained in standard practice without any advertising.

Five patients (62.5\%) were males and $3(37.5 \%)$ were females. Subjects were between 50 to 69 years old, with a mean age, height, weight, and BMI of 50.62 years, 174.75 $\mathrm{cm}, 77.50 \mathrm{~kg}$, and 25.30 , respectively. All subjects belonged to the Caucasian ethnic group. Due to small sample, a statistically significant difference was evidenced between sex for height and weight $(p=0.046$ and $p=0.009$, respectively) (Table 1 ).

No relevant findings were evidenced either in the medical history or during physical examination and no concomitant medication was recorded during the screening evaluation.

No major protocol deviations occurred concerning the scheduled visits.

Out of 8 US parameters evaluated during the study, 4 (Baker's cyst, synovial fluid, enthesopathies, lateral osteophytes) improved, 3 (articular cartilage damage, medial meniscal protrusion, medial osteophytes, lateral meniscal protrusion,) did not change between $B L$ and final visit (Figure 3). Due to the small number of patients evaluated, no statistically significant differences were found for any of the US parameters, applying the McNemar tests between 8-Week visit and the BL visit.

ROM values improved at week 4 and week 8 visit during the study (Table 2). Active Knee Flexion (AKF), Passive Knee Extension (PKE) and Passive Knee Flexion (PKF) values increased in a time-dependent manner, reaching statistical significance in comparison with BL.

VAS at rest values evidenced statistically significant differences between 4-Week and BL visit, and between 8Week and BL visit, ( $p=0.024$ and $p=0.011$, respectively). Also, the VAS on moving and on pressing values reached statistical significance at week 4 and 8 in comparison with BL values (Table 3).

Actigraphy, as optional test, was performed on few patients only. Logistical and technical inconveniences (difficulty for patients in maintaining the Velcro band in the correct position and battery-not well powered for the scheduled time of a week) did not allow to evaluate this device.

The Pearson correlation coefficient (PCC) was calculated between difference of VAS at rest, on moving and on pressing (Visit 1 vs Visit 2, Visit 1 vs. Visit 3) and the variation of 4 ROM parameters. All the correlations increased in absolute values from BL to 4-Week visit and from BL to final visit. The highest correlations in absolute

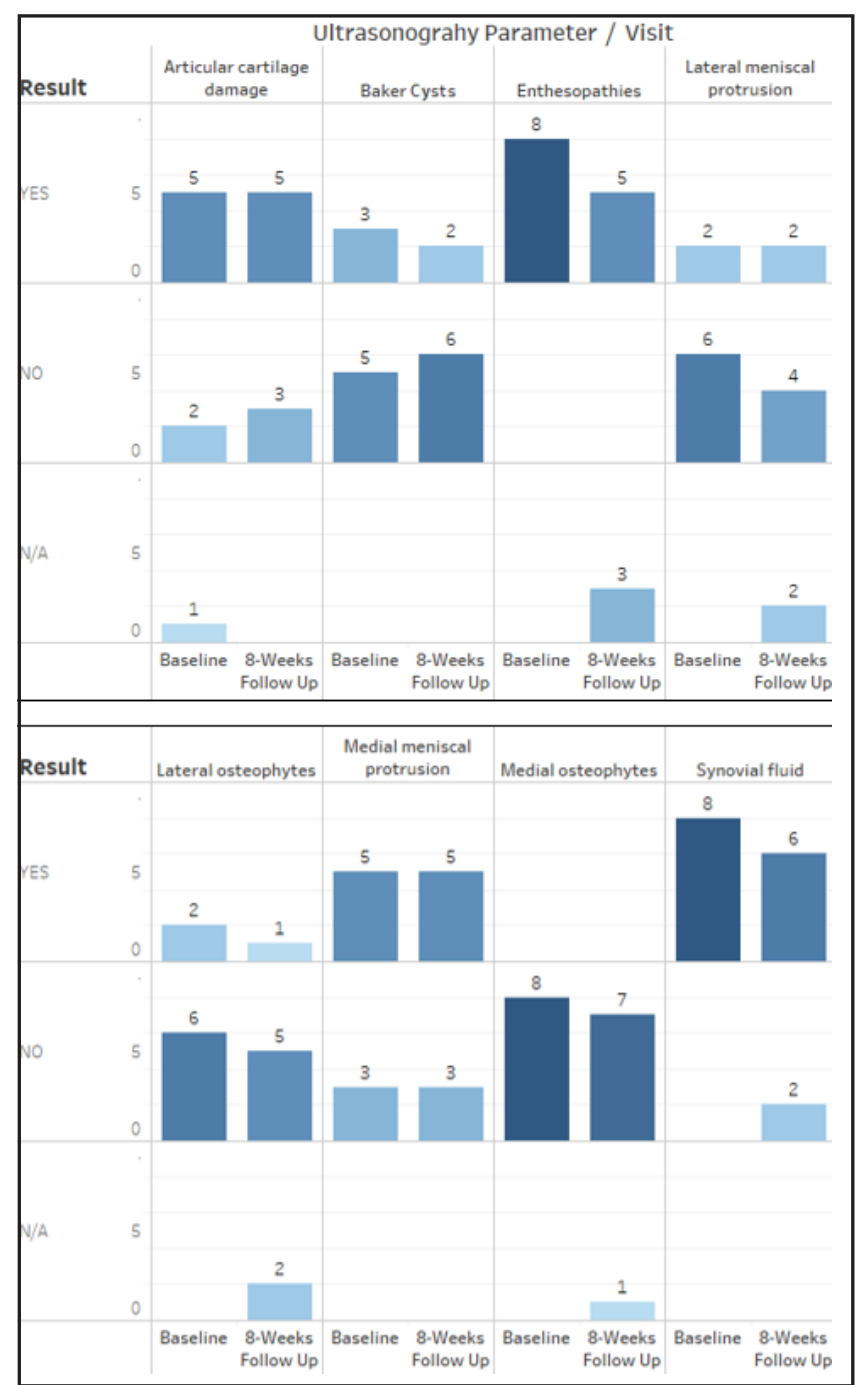

Fig. 3. Ultrasonography at baseline and 8-weeks follow-up visit: no. of patients and parameters evaluation.

values were found from $B L$ to final visit in PKF and in PKE (0.45 and -0.44 , respectively) (Table 4).

It was not possible to test the correlation between US and VAS, because no statistically significant differences were found for US parameters.

The analysis of KOOS questionnaire normalized answers scores evidenced statistically significant differences comparing BL visit with Week 4 and 8 (Figure 4). No adverse event was evidenced during the trial period. This 


\begin{tabular}{|c|c|c|c|c|c|c|c|}
\hline AKF & \multicolumn{2}{|c|}{ Baseline Visit (V1) } & \multicolumn{2}{|c|}{ 4-Weeks Visit (V2) } & \multicolumn{2}{|c|}{ 8-Weeks Visit (V3) } & p-value \\
\hline $\mathrm{N}$ & \multicolumn{2}{|c|}{8} & \multicolumn{2}{|c|}{8} & \multicolumn{2}{|c|}{8} & \multirow{5}{*}{$\begin{array}{l}\mathrm{V} 1 \mathrm{vs} \mathrm{V} 2 \\
\mathrm{p}=0.015^{\star} \\
\mathrm{V} 1 \mathrm{vs} \mathrm{V} 3 \\
\mathrm{p}=0.004\end{array}$} \\
\hline Mean $\pm S D$ & \multicolumn{2}{|c|}{$128.12 \pm 5.51$} & \multicolumn{2}{|c|}{$130.62 \pm 6.55$} & \multicolumn{2}{|c|}{$133.25 \pm 6.30$} & \\
\hline Median & \multicolumn{2}{|c|}{127.5} & \multicolumn{2}{|c|}{131.0} & \multicolumn{2}{|c|}{134.5} & \\
\hline Minimum & \multicolumn{2}{|l|}{120} & \multicolumn{2}{|l|}{120} & \multicolumn{2}{|c|}{125} & \\
\hline Maximum & \multicolumn{2}{|l|}{135} & \multicolumn{2}{|l|}{140} & \multicolumn{2}{|c|}{144} & \\
\hline PKE & \multicolumn{2}{|c|}{ Baseline Visit (V1) } & \multicolumn{2}{|c|}{ 4-Weeks Visit (V2) } & \multicolumn{2}{|c|}{ 8-Weeks Visit (V3) } & p-value \\
\hline $\mathrm{N}$ & \multicolumn{2}{|c|}{8} & \multicolumn{2}{|c|}{8} & \multicolumn{2}{|c|}{8} & \multirow{5}{*}{$\begin{array}{l}\mathrm{V} 1 \text { vs } V 2 \\
p=0.020^{*} \\
V 1 \text { vs } V 3 \\
p=0.014^{*}\end{array}$} \\
\hline Mean \pm SD & \multicolumn{2}{|l|}{$-3.50 \pm 3.07$} & $-1.25 \pm$ & & & $5 \pm 1.49$ & \\
\hline Median & -5 & & 0 & & 0 & & \\
\hline Minimum & -8 & & -6 & & -4 & & \\
\hline Maximum & 0 & & 0 & & 0 & & \\
\hline PKF & Baseline V & $t$ (V1) & 4-Wee & Visit (V2) & & leeks Visit (V3) & p-value \\
\hline $\mathrm{N}$ & 8 & & 8 & & 8 & & \\
\hline Mean \pm SD & $126.39 \pm 5$ & & 130.62 & 5.97 & & $62 \pm 5.58$ & $p=0.004^{*}$ \\
\hline Median & 127.5 & & 132.5 & & & & \\
\hline Minimum & 120 & & 120 & & & & V1 vs V3 \\
\hline Maximum & 135 & & 140 & & & & \\
\hline VAS at Re & $(\mathrm{mm})$ & Basel & V Visit & Week 41 & & Week 8 Visit & p-value \\
\hline $\mathrm{N}$ & & 8 & & 8 & & 8 & V1 ys V2 \\
\hline Mean $\pm S D$ & & 38.88 & 3.12 & $20.88 \pm 9$ & & $6.38 \pm 6.76$ & $0=0024^{2}$ \\
\hline Median & & 39.50 & & 21.50 & & 5.00 & $\mathrm{p}=0.024^{*}$ \\
\hline Minimum & & 9.00 & & 3.00 & & 1.00 & V1 vs V/3 \\
\hline Maximum & & 66.00 & & 34.00 & & 21.00 & $\mathrm{p}=0.011^{*}$ \\
\hline VAS on $\mathrm{m}$ & ing (mm) & Basel & Visit & Week 41 & & Week 8 Visit & p-value \\
\hline $\mathrm{N}$ & & 8 & & 8 & & 8 & V1 vs V2 \\
\hline Mean \pm SL & & 59.75 & 5.05 & $36.75 \pm 17$ & & $18.88 \pm 10.52$ & $p=0.005^{*}$ \\
\hline Median & & 63.5 & & 37.0 & & 16.0 & \\
\hline Minimum & & 36 & & 6 & & 8 & V1 vs V3 \\
\hline Maximum & & 83 & & 56 & & 41 & $p<0.001^{*}$ \\
\hline VAS on $p$ & $\operatorname{sing}(\mathrm{mm})$ & Basel & Visit & Week 41 & & Week 8 Visit & p-value \\
\hline $\mathrm{N}$ & & 8 & & 8 & & 8 & \\
\hline Mean $\pm S D$ & & 63.75 & 2.69 & $46.88 \pm 13$ & & $30.75 \pm 11.46$ & $p=0.005^{*}$ \\
\hline Median & & 64.5 & & 43.0 & & 29.0 & 13 \\
\hline Minimum & & 41 & & 32 & & 20 & 73 \\
\hline Maximum & & 81 & & 68 & & 56 & \\
\hline
\end{tabular}

Table 2

ROM (AKF, PKE, PKF) VALUES (DEGREES) DURING THE STUDY. Significant differences are marked with *
Table 3

VISUAL ANALOGUE SCALE (VAS) AT REST, ON MOVING AND ON PRESSING DURING THE STUDY. Significant differences are marked with *.

\begin{tabular}{|c|c|c|c|c|}
\hline VAS at rest & AKF & AKE & PKF & PKE \\
\hline V1 vs V2 & 0.37 & -0.17 & 0.25 & -0.40 \\
\hline V1 vs V3 & 0.41 & -0.26 & 0.45 & -0.44 \\
\hline VAS on moving (mm) & & & & \\
\hline V1 vs V2 & -0.52 & 0.35 & -0.62 & 0.32 \\
\hline V1 vs V3 & -0.59 & -0.02 & -0.60 & 0.12 \\
\hline VAS on pressing (mm) & & & & \\
\hline V1 vs V2 & -0.43 & 0.35 & -0.56 & 0.31 \\
\hline
\end{tabular}

CORRELATION BETWEEN VAS AT REST, ON MOVING AND ON PRESSING (mm) AND ROM PARAMETERS.

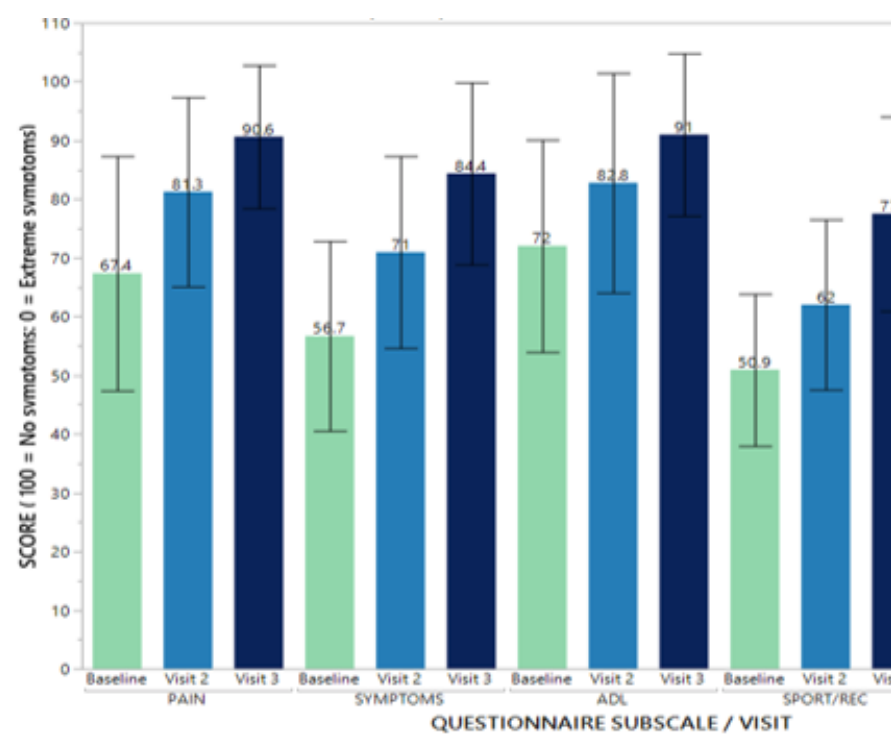

QUESTIONNAIRE SUBSCALE / VISIT

positive evaluation was confirmed by patient diaries data and by the Syalox ${ }^{\circledR} 300$ Plus oral administration compliance (100\% for all patients).

\section{Limitation}

The small sample size, only one clinical site involved (with the risk of selection bias), the non-randomized design and the absence of a control group were the main limitations of this pilot study. The KOOS questionnaire was chosen due to the extremely expensive cost of WOMAC.

\section{Conclusions}

Oral HA in patients with mild to moderate knee $O A$ is widely used in clinical practice by medical doctors in 
Europe, the US and Asia. Several clinical studies have shown moderate efficacy of oral HA treatments in reducing pain and improving knee functionality, with no side effects [16]. No trial analyzed the potential correlation between subjective evaluation (i.e. by VAS) and objective measurements. To test the feasibility of using a device able to supply objective data to correlate with VAS in a future main study, we tested in the present pilot study US, ROM and actigraphy. The objectives of the pilot study were achieved:

-US and ROM were tested and could be used in the future study as objective measurements to correlate the improvement of the knee mobility with the pain reduction of the affected knee. The PCC was only calculated between ROM and VAS. US values decreased during the study period, but the test could not be performed due to the small sample size of patients.

-Logistic and technical inconveniences did not allow to verify actigraphy in this study, even if finding of the 2 collected cases were suggestive of the possibility to follow the increasing of patient mobility and the decrease of pain during the study period. For this reason, we decided not to use the actigraph as primary outcome in the future main study, but to use this device with exploratory intention only.

-The collected data regarding recruitment capability ( 8 patients/month/site) and study procedures evidenced a realistic estimation of time and budget for the main study.

-Preliminary data on efficacy of objective measurements (US, ROM) and subjective parameters (VAS, KOOS questionnaire) showed significant improvements in knee osteoarthritis and will be used for the sample size calculation of the main future study.

Acknowledgments: Warm thanks to Ramona Petrita and AndreeaDenisa Toma for supporting in data management, Dragos Nica for proofreading and Marius Ardelean for statistical analysis. A grant support was received from River Pharma, Orio Litta- Italy; (http:// www.riverpharma.it).

\section{References}

1.BHATIA, D., BEJARANO, T., NOVO, M. Current interventions in the management of knee osteoarthritis. J. Pharm. Bioallied Sci., 5, no. 1, 2013, p. 30

2.*** CENTERS FOR DISEASE CONTROL AND PREVENTION. OSTEOARTHRITIS. http://www.cdc.gov/arthritis/basics/ osteoarthritis.htm. Accessed September 1, 2018.

3.RINGDAHL, E., PANDIT, S. Treatment of knee osteoarthritis. Am. Fam. Physician., 83, 2011, p. 1287

4.VOS, T., FLAXMAN, A.D., NAGHAVI, M., LOZANO, R., MICHAUD, C., EZZATI, M., et al. Years lived with disability [YLDs] for 1160 sequelae of 289 diseases and injuries 1990-2010: a systematic analysis for the Global Burden of Disease Study 2010. Lancet, 380, 2012, p. 2163 5.CUTOLO, M., BERENBAUM, F., HOCHBERG, M., PUNZI, L., REGINSTER, J.Y. Commentary on recent therapeutic guidelines for osteoarthritis. Semin. Arthritis Rheum., 44, no. 6, 2015, p. 611 6.BRUYERE, O., COOPER, C., PELLETIER, J.P., BRANCO, J., BRANDI, M.L., GUILLEMIN, F., HOCHBERG, M.C., KANIS, J.A., KVIEN, T.K., MARTEL-PELLETIER, J., RIZZOLI, R., SILVERMAN, S., REGINSTER, J.Y. An algorithm recommendation for the management of knee osteoarthritis in Europe and internationally: a report from a task force of the European Society for Clinical and Economic Aspects of Osteoporosis and Osteoarthritis [ESCEO]. Semin. Arthritis Rheum. 44, 2014, p. 253

7.BRUYĖRE, O., COOPER, C., PELLETIER, J.P., MAHEU, E., RANNOU, F., BRANCO, J., LUISA BRANDI, M., KANIS, J.A., ALTMAN, R.D., HOCHBERG, M.C., MARTEL-PELLETIER, J., REGINSTER, J.Y. A consensus statement on the European Society for Clinical and Economic Aspects of Osteoporosis and Osteoarthritis [ESCEO] algorithm for the management of knee osteoarthritis-From evidencebased medicine to the real-life setting. Semin. Arthritis Rheum. 45, no. 4 Suppl, 2016, p. S3

8.BRUYĖRE, O., BURLET, N., DELMAS, P.D., RIZZOLI, R., COOPER, C., REGINSTER, J.Y. Evaluation of symptomatic slow-acting drugs in osteoarthritis using the GRADE system. BMC Musculoskelet Disord. 16, no. 9, 2008, p. 165

9.SANSONE, V., CONSONNI, O., MAIORANO, E. Nutraceuticals and chondroprotective agents for the treatment of osteoarthritis: a narrative review. A controversial resource in the treatment of osteoarthritis. Minerva Ortop. Traumatol. 65, 2014, p. 61

10.BANNURU, R.R., SCHMID, C.H., KENT, D.M., VAYSBROT, E.E., WONG, J.B., MCALINDON, T.E. Comparative effectiveness of pharmacologic interventions for knee osteoarthritis: a systematic review and network meta-analysis. Ann. Intern. Med. 162, no. 1, 2015, p. 46

11.NAVARRO-SARABIA, F., CORONEL, P., COLLANTES, E., NAVARRO, F.J ., DE LA SERNA, A.R., NARANJ O, A., GIMENO, M., HERREROBEAUMONT, G. AMELIA study group. A 40-month multicentre, randomised placebo-controlled study to assess the efficacy and carryover effect of repeated intra-articular injections of hyaluronic acid in knee osteoarthritis: the AMELIA project. Ann. Rheum. Dis. 70, no. 11, 2011, p. 1957

12.WADDELL, D.D., BRICKER, D.C. Total knee replacement delayed with Hylan G-F 20 use in patients with grade IV osteoarthritis. J. Manag. Care. Pharm. 13, no. 2, 2007, p. 113

13.BALOGH, L., POLYAK, A., MATHE, D., KIRALY, R., THUROCZY, J., TEREZ, M., JANOKI, G., TING, Y., BUCCI, L.R., SCHAUSS, A.G. Absorption, uptake and tissue affinity of high-molecular-weight hyaluronan after oral administration in rats and dogs. J. Agric. Food. Chem. 56, no. 22, 2008, p. 10582

14.ALTMAN, R.D., MANJOO, A., FIERLINGER, A., NIAZI, F., NICHOLLS, $M$. The mechanism of action for hyaluronic acid treatment in the osteoarthritic knee: a systematic review. BMC Musculoskelet. Disord. 16,2015, p. 321

15.DU SOUICH, P. Absorption, distribution and mechanism of action of SYSADOAS. Pharmacol. Ther. 142, no. 3, 2014, p. 362

16.OE, M., TASHIRO, T., YOSHIDA, H., NISHIYAMA, H., MASUDA, Y., MARUYAMA, K., KOIKEDA, T., MARUYA, R., FUKUI, N. Oral hyaluronan relieves knee pain: a review. Nutr. J. 15, 2016, p. 11

17.GUADAGNA, S., BARATTINI, D.F., ROSU, S. Oral hyaluronan for the treatment of knee osteoarthritis: a systematic review. Progress in Nutrition 20, 2018, p. 4

18.TASHIRO, T., SEINO, S., SATO, T., MATSUOKA, R., MASUDA, Y., FUKUI. N. Oral administration of polymer hyaluronic acid alleviates symptoms of knee osteoarthritis: a double-blind, placebo-controlled study over a 12-month period. Sci. World J. 2012, 2012, p. 1.

19.IWASO, H., SATO, T. Examination of the efficacy and safety of oral administration of Hyabest ${ }^{\circledR}[\mathrm{J}]$ ]-highly-pure hyaluronic acid for knee joint pain. J. J pn. Soc. Clin. Sports Med. 58, 2009, p. 566

20.NAGAOKA, I., NABESHIMA, K., MURAKAMI, S., YAMAMOTO, T., WATANABE, K., TOMONAGA, A., YAMAGUCHI, $H$. Evaluation of the effects of a supplementary diet containing chicken comb extract on symptoms and cartilage metabolism in patients with knee osteoarthritis. Exp. Ther. Med. 1, 2010, p. 817

21.MOLLER, I., MARTINEZ-PUIG, D., CHETRIT, C. Oral administration of a natural extract rich in hyaluronic acid for the treatment of knee OA with synovitis: a retrospective cohort study. Clin. Nutr. Suppl. 4, 2009, p. 171

22.SANCHEZ, J., BONET, M.L., KEIJER, J., VAN SCHOTHORST, E.M., MÖLLLER, I., CHETRIT, C., MARTINEZ-PUIG, D., PALOU, A. Blood cells transcriptomics as source of potential biomarkers of articular health improvement: effects of oral intake of a rooster combs extract rich in hyaluronic acid. Genes Nutr. 9, 2014, p. 417

23.SOLA, R., VALLS, R.M., MARTORELL, I., GIRALT, M., PEDRET, A., TALTAVULL, N., et al. A low-fat yoghurt supplemented with a rooster comb extract on muscle joint function in adults with mild knee pain: a randomized, double blind, parallel, placebo-controlled, clinical trial of eûcacy. Food Funct. 6, no.11, 2015, p. 3531 
24.MARTINEZ-PUIG, D., MOLLER, I., FERNANDEZ, C., CHETRIT, C. Efficacy of oral administration of yoghurt supplemented with a preparation containing hyaluronic acid [Mobilee ${ }^{\mathrm{TM}}$ ] in adults with mild joint discomfort: a randomized, double-blind, placebo-controlled intervention study. Mediterr. J. Nutr. Metab. 6, 2013, p. 63

25.WYLDE, V., LENGUERRAND, E., BRUNTON, L., DIEPPE, P., GOOBERMAN-HILL, R., MANN, C., BLOM, A.W. Does measuring the range of motion of the hip and knee add to the assessment of disability in people undergoing joint replacement? Orthop. Traumatol. Surg. Res. 100, no. 2, 2014, p. 183

26.PROVERB RESOURCES: ASHANTI PROVERBS FROM GHANA in: http://cogweb.ucla.edu/Discourse/Proverbs/Ashanti.html Accessed September 1, 2018

27.THABANE, L., MA, J., CHU, R., CHENG, J., ISMAILA, A., RIOS, L.P., ROBSON, R., THABANE, M., GIANGREGORIO, L., GOLDSMITH, C.H. A tutorial on pilot studies: the what, why and how. BMC Med. Res. Methodol. 10, 2010, p. 1

28.LANCASTER, G.A., DODD, S., WILLIAMSON, P.R. Design and analysis of pilot studies: recommendations for good practice. J. Eval. Clin. Pract. 10, no. 2, 2004, p. 307

29.BROWN, P., BRUNNHUBER, P., CHALKIDOU, K., CHALMERS, I., CLARKE, M., FENTON, M., FORBES, C., GLANVILLE, J., HICKS, N.J., MOODY, J., TWADDLE, S., TIMIMI, H., YOUNG, P. How to formulate research recommendations. British Medical J ournal 333, 2006, p. 804
30.J OHNS HOPKINS ARTHRITIS CENTER. ACR CLINICAL CLASSIFICATION CRITERIA FOR OSTEOARTHRITIS OF THE KNEE. Accessed September 1, 2018: https://www.hopkinsarthritis.org/ physician-corner/education/arthritis-education-diagnostic-guidelines/ 31.KOHN, M.D., SASSOON, A.A., FERNANDO, N.D. Classifications in Brief: Kellgren-Law rence Classification of Osteoarthritis. Clin. Orthop. Relat. Res. 474, no. 8, 2016, p. 1886

32.SERBAN, O., POROJAN, M., DEAC, M., COZMA, F., SOLOMON, C., LENGHEL, M., MICU, M., FODOR, D. Pain in bilateral knee osteoarthritis - correlations between clinical examination, radiological, and ultrasonographical findings. Med. Ultrason. 18, no. 3, 2016, p. 318

33.LEQUESNE, M., DOUGADOS, M., ABITEBOUL, M., BONTOUX, D., BOUVENOT, G., CHICHEPORTICHE, V., DREISER, R.L., ROPSY, R., MAHEU, E., MAZIĖRES, B., et al. How to evaluate the long-term course of osteoarthritis. Tests for trials of fundamental treatments (spine excluded). Rev. Rhum. Mal. Osteoartic. 57, no. 9, 1990, p. $24 S$

34.ONOFREI, R.R. Cross-Cultural Adaptation of KOOS. Romanian Version. http://www.koos.nu/koosromanian.pdf Accessed September 1,2018

35.ANDOR, B.C., BARATTINI, D.F., DOGARU, D.E., GUADAGNA, S., ROSU, S. Pilot, open non-controlled trial to assess the feasibility of implementing objective parameters as primary endpoints in a clinical trial with patients affected by knee osteoarthritis. JMIR Res. Protoc. 2019 accepted.

Manuscript received: 21.03 .2019 